\title{
Concepções de avaliação de professores e alunos da rede pública do Estado do Paraná
}

\author{
MARLISA BERNARDI DE ALMEIDA* \\ LUCIANA DEL CASTANHEL PERON** \\ RICARDO DESIDÉRIO***
}

\begin{abstract}
RESUMO
Este trabalho objetivou investigar as concepções de avaliação da aprendizagem de professores de Matemática e alunos das séries finais do ensino fundamental da rede pública do Estado do Paraná e outras questões importantes referentes às práticas avaliativas presentes no processo de ensino e aprendizagem. O estudo possibilitou analisar as respostas aos questionários aplicados a professores e alunos desse nível de ensino, procurando categorizá-las e associá-las a um referencial teórico adequado a cada análise feita. Os resultados demonstraram que as concepções se associaram frequentemente à verificação da aprendizagem, servindo ao professor, prioritariamente. Tais resultados, longe de serem conclusivos, ampliam, no entanto, nossa compreensão a respeito da visão dos docentes e discentes sobre a avaliação, fornecendo um conjunto de informações bastante relevante, tanto do ponto de vista da reflexão teórica quanto da prática educativa.
\end{abstract}

Palavras-chave: Avaliação da aprendizagem, Relações professor-alunos, Processo de ensinoaprendizagem.

\section{RESUMEN}

Este trabajo tuvo el objetivo de investigar el concepto de evaluación del aprendizaje de profesores de Matemática y alumnos de los últimos años de la enseñanza básica del sistema público del Estado de Paraná y de investigar también otras cuestiones importantes referentes a las prácticas de evaluación presentes en el proceso de enseñanza-aprendizaje. El estudio permitió analizar las respuestas a los cuestionarios realizados a profesores y alumnos de este nivel de la enseñanza. Se intentó categorizar y asociar dichas respuestas a un referencial teórico adecuado a cada análisis realizado. Los resultados demostraron que el concepto de evaluación se asoció frecuentemente a la verificación del aprendizaje, sirviéndole en especial al profesor. Tales resultados, lejos de ser conclusivos, amplían, sin embargo, nuestra comprensión al respecto de la visión que docentes y estudiantes tienen sobre la evaluación, suministrando un conjunto de informaciones bastante relevantes, tanto desde el punto de vista de la reflexión teórica como de la práctica educativa.

Palabras clave: Evaluación del aprendizaje, Relaciones profesor-alumno, Proceso de enseñanza-aprendizaje.

\footnotetext{
* Mestranda do Programa de Mestrado em Educação para a Ciência e o Ensino da Matemática da Universidade Estadual de Maringá (UEM) (marlisabernardi@yahoo.com.br).

** Mestranda do Programa de Mestrado em Educação para a Ciência e o Ensino da Matemática da Universidade Estadual de Maringá (UEM) (lucianaperon@ @otmail.com).

**** Mestrando do Programa de Mestrado em Educação para a Ciência e o Ensino da Matemática da Universidade Estadual de Maringá (UEM) (rickdesiderio@hotmail.com).
} 


\section{ABSTRACT}

This study aimed to investigate the evaluation conceptions of Mathematics teachers' and students' learning in the last years of elementary public school of the State of the Paraná, as well as other important issues concerning evaluation practices in the teaching and learning process. The study analyzed the answers to questionnaires completed by teachers and students at this educational level, trying to categorize them and assign them to a theoretical framework appropriate for each analysis. The results showed that the conceptions are often associated with the verification of learning and are mainly relevant to the teacher. These results are far from conclusive, but they extend our understanding of the view teachers and students have about evaluation, providing a set of highly relevant information, both from the theoretical reflection and educational practice perspectives.

Keywords: learning assessment, teacher-student relations, teaching-learning process.

\section{INTRODUÇÃO}

Conhecendo o histórico da avaliação no cotidiano escolar, elucidado por Luckesi (2002), percebemos que a prática da avaliação da aprendizagem que vem sendo desenvolvida nas muitas instituições de ensino nos remete a uma posição de poucos avanços.

Diante dessa realidade escolar, nos propomos a realizar este estudo com o objetivo principal de investigar as concepções de avaliação da aprendizagem para professores de Matemática e alunos das séries finais do ensino fundamental da rede pública do Estado do Paraná. Tendo essas ideias como ponto de partida, procuramos responder a seguinte questão norteadora da investigação: Quais as concepções predominantes de avaliação da aprendizagem dos professores de Matemática e alunos dos últimos anos do ensino fundamental da rede pública do Estado do Paraná?

Nesse sentido, pretendemos identificar as concepções e finalidades da avaliação, os instrumentos avaliativos mais utilizados na disciplina de Matemática, as dificuldades que os professores encontram no ato de avaliar e como é tratado o erro no processo avaliativo.

A hipótese levantada é que a avaliação não tem sido utilizada como elemento que auxilie de fato no processo de ensino e aprendizagem, perdendo-se em mensurar e quantificar o saber, deixando de identificar e estimular os potenciais individuais e coletivos dos educandos.

Considerando as complexidades que permeiam o processo de avaliação da aprendizagem, acreditamos que identificar e analisar as opiniões e percepções dos professores e estudantes pode trazer importantes elementos de reflexão sobre o tema em estudo. 


\section{PROCEDIMENTOS METODOLÓGICOS}

A metodologia adotada foi a pesquisa de campo, por meio de um estudo exploratório de cunho qualitativo; entretanto, não desprezamos o aspecto quantitativo.

Participaram da pesquisa de campo 12 docentes de Matemática das séries finais do ensino fundamental da rede pública do Estado do Paraná, sendo no mínimo dois e no máximo cinco de cada uma das seguintes regiões do Estado: norte (Londrina e Maringá), centro-oeste (Laranjeiras do Sul) e oeste (Medianeira). Quanto aos discentes, participaram igualmente 12 estudantes que estão cursando as séries finais do ensino fundamental e são alunos dos professores pesquisados.

Os instrumentos utilizados para a coleta de dados foram questionários com perguntas abertas, aplicados aos professores e alunos. O questionário dos professores foi composto por dois blocos de questões, assim designados:

- Identificação - que abordou informações sobre idade, formação inicial, atuação profissional e formação continuada;

- Sobre a avaliação da aprendizagem em Matemática - contendo dez questões abertas que objetivavam identificar, nas respostas dadas pelos professores, as concepções e finalidades da avaliação, os instrumentos de avaliação mais utilizados, as dificuldades que encontram no ato de avaliar e como é tratado o erro no processo avaliativo.

O questionário foi respondido individualmente durante os momentos denominados de Hora Atividade dos professores, e para respondê-lo cada professor levou cerca de uma hora.

O instrumento aplicado aos alunos foi semelhante ao dos professores, com pequenas alterações em quatro questões do primeiro bloco e em duas do segundo. Essas alterações foram feitas para adequar o questionário ao público que o responderia, neste caso, os alunos. Para responder ao questionário proposto, os alunos foram retirados das salas de aula em horários distintos durante a semana e responderam as questões individualmente.

Como afirmamos anteriormente, as questões propostas aos professores foram semelhantes àquelas propostas aos alunos, pois nossa intenção foi observar se há algum consenso ou contrassenso entre eles, no que diz respeito aos aspectos que consideramos relevantes e que se fazem presente na avaliação da aprendizagem. Destacamos que neste artigo não faremos a análise de todas as questões propostas nos questionários, haja vista que ultrapassaria o limite de páginas permitido, mas somente daquelas que julgamos mais condizentes com nosso objetivo principal. 
Para a análise qualitativa das informações obtidas, utilizamos a Técnica de Análise de Conteúdo proposta por Bardin (1979), um conjunto de técnicas de análise de comunicação que utiliza procedimentos sistemáticos e objetivos de descrição do conteúdo das mensagens, a qual permitiu confrontar metodologicamente a verificação e interpretação dos significados das mensagens (manifestos ou subjacentes) atribuídos à avaliação da aprendizagem pelos participantes da pesquisa. Na discussão dos resultados, procuramos comparar as informações obtidas sob o ponto de vista dos professores e alunos com os dados disponíveis na literatura especializada em avaliação da aprendizagem escolar.

A análise dos dados coletados, a partir dos questionários, foi realizada da seguinte forma: as questões abertas foram classificadas em categorias, conforme orientação de Bardin (1979), que emergiram da análise das respostas dos alunos e professores, as quais foram agrupadas de acordo com frases ou palavras que havia em comum, para que fossem analisadas à luz da literatura sobre avaliação da aprendizagem.

Apesar de ser uma análise de conteúdo, julgamos necessário fazer uma análise quantitativa das categorias que emergiram da pré-análise e da exploração do material, por acreditarmos que possibilita um melhor entendimento e visualização dos dados coletados. Por essa razão, os dados quantitativos foram complementares, mas possibilitaram a caracterização do grupo de professores e alunos, facilitando de certa forma a categorização das respostas.

\section{DISCUSSÃO E RESULTADOS}

A complexidade de elementos presentes no processo de avaliação da aprendizagem indica que não existe uma única concepção de avaliação. Na verdade, existem diferentes formas possíveis de abordar o ato de avaliar. De acordo com Libâneo (1999), a avaliação é uma análise qualitativa sobre dados considerados importantes do processo de ensino e aprendizagem que auxilia o professor a tomar decisões sobre o seu trabalho.

Concordamos com o autor, mas acrescentamos que a avaliação deve auxiliar também o discente, pois ela possibilita ao aluno tomar decisões sobre seus estudos, dificuldades e progressos. A avaliação da aprendizagem, sob esta conotação, serve tanto para o aluno quanto para o professor.

Os sujeitos de nossa pesquisa foram 12 professores, os quais possuem graduação em Matemática, especialização em área pedagógica e fazem cursos de formação continuada promovidos pelo Governo do Estado do Paraná. São, na maioria, do sexo feminino (66,6\%), e 
o tempo que estão atuando em sala de aula varia de cinco a dez anos de efetivo exercício. Os alunos pesquisados cursam a sétima e oitava séries do ensino fundamental, e alguns (10\%) já passaram pela reprovação em certo período de sua vida escolar. Entretanto, conforme as respostas coletadas, a maioria deles $(75 \%)$, atualmente, consegue ter bom rendimento acadêmico.

O foco de nossa investigação recaiu sobre o significado da avaliação da aprendizagem para os professores e alunos participantes da pesquisa. Por isso, nossa primeira questão se referiu a esse aspecto central: O que você entende por avaliação da aprendizagem?

Observamos que as respostas dos 12 professores foram semelhantes quanto à concepção de avaliação da aprendizagem escolar, o que permitiu agrupá-las em três categorias, quais sejam:

- Quantificar o conhecimento do aluno: $16 \%$

P1: Avaliação da aprendizagem escolar para mim é quantificar o que o aluno aprendeu o que não aprendeu e o que precisa ser revisto.

P6: É uma maneira de ver o quanto o aluno assimilou daquilo que foi trabalhado em sala de aula.

- Verificação da aprendizagem: $68 \%$

P2: Avaliação é um instrumento para verificar a aprendizagem efetiva do aluno.

P3: É verificar o interesse do aluno ao conteúdo e sua participação durante as aulas, ver se ele aprendeu ou não.

P8: A avaliação permite ao professor verificar a relação do aluno com o conhecimento, como ele atribui significado ao que aprendeu e conseguiu aplicar em situações que exigem raciocínio matemático.

P10: É verificar o que o aluno já aprendeu, é o momento do processo ensino e aprendizagem que permite tanto ao professor quanto ao aluno verificar se os objetivos propostos foram alcançados.

P4: Verificar qual o rendimento que meus alunos possuem quanto ao conteúdo explicado.

- Verificar a metodologia de ensino ou o desempenho do docente: $16 \%$

P7: A avaliação da aprendizagem fornece informações para que o professor possa fazer uma reflexão sobre seu trabalho em sala de aula, e com isso buscar métodos mais pertinentes que possam auxiliar os alunos a superar as dificuldades encontradas. 
P9: É uma maneira de verificar se o que eu estou trabalhando em sala de aula está sendo assimilado pelos alunos, para que possa, se preciso, mudar minha estratégia de ensino.

É possível notar que em todas as respostas dos professores, revela-se, mesmo que sutilmente, a preocupação com a aprendizagem do aluno. Isso mostra que apesar de a avaliação ainda ser considerada pela maioria desses profissionais uma verificação da aprendizagem, demonstram, nas linhas e entrelinhas, interesse pela aprendizagem dos seus alunos. Observamos também que, os professores entrevistados, em nenhum momento abordaram a avaliação como um fim em si mesma e tampouco sob a conotação de castigo ou de mera classificação dos alunos. Nesse sentido, apontamos possíveis nuances de mudança na concepção de avaliação dos professores pesquisados.

De acordo com nossa análise e o diálogo com esses profissionais, notamos que a avaliação assume um caráter importante no processo de ensino e aprendizagem, contudo ainda aquém daquilo que se espera.

Além disso, percebemos, entre os professores pesquisados, uma preocupação em reafirmar a necessidade de mudanças mais concretas na avaliação dos alunos e uma tendência em ampliar seus conceitos de avaliação, indo além da medida de desempenho do aluno, pois nos depoimentos finais (75\%) notam a importância do estudo sobre esse tema para posterior melhoria em sua prática pedagógica. Vejamos alguns:

P9: Certamente há muito o que mudar e melhorar no tocante à avaliação escolar. Os cursos que temos feito e os grupos de estudos promovidos pela SEED nos auxiliam a ampliar nossa visão e a perceber que a avaliação deve ir além daquilo que estamos acostumados a fazer em sala de aula.

P12: Através das leituras que temos feito nos grupos de estudos, percebo que há a necessidade de mudança, não somente na questão da avaliação, mas na estrutura escolar como um todo, para que a aprendizagem dos alunos seja melhor atendida.

Por meio dos depoimentos dos professores pesquisados, acreditamos que estão procurando encaminhar-se na concepção de avaliação proposta por Luckesi (2002, p. 81):

[...] A avaliação deverá ser assumida como um instrumento de compreensão do estágio de aprendizagem em que se encontra o aluno, tendo em vista tomar decisões suficientes e satisfatórias para que possa avançar no seu processo de aprendizagem. Se é importante aprender aquilo que se ensina na escola, a função da avaliação será 
possibilitar ao educador condições de compreensão do estágio em que o aluno se encontra, tendo em vista poder trabalhar com ele para que saia do estágio defasado em que se encontra e possa avançar em termos dos conhecimentos necessários [...].

Dessa forma, a avaliação da aprendizagem possibilita a tomada de decisão e a melhoria da qualidade de ensino, informando as ações em desenvolvimento e a necessidade de regulações constantes.

Quanto ao item dois do questionário, que se referia às finalidades da avaliação, as respostas dos professores forneceram dados que foram agrupados em duas categorias:

- Verificação da aprendizagem do aluno: 56\%

- Diagnosticar possíveis falhas e o que deve ser revisto: $44 \%$

Selecionamos algumas respostas que ilustram significativamente essas categorias:

P2: Verificar o que o aluno aprendeu e não aprendeu.

P5: Avaliar minha própria prática, ver possíveis falhas e o que deve ser revisto.

P10: Diagnosticar possíveis falhas do professor e do aluno.

P7: Verificar qual intervenção deve ser feita junto ao aluno.

No questionário, foi solicitado que indicassem três finalidades de suas práticas de avaliação, porém a maioria dos professores pesquisados não conseguiu citá-las. Aqueles que responderam mencionam apenas duas, as quais se enquadram nas categorias anteriormente descritas.

Diante dos dados coletados e categorizados, observamos, pelas respostas, que os professores ainda não têm discernimento suficiente para identificar quais são os reais objetivos do ato de avaliar, e aqueles que acreditam saber quais são, comumente, reportam-se à concepção de avaliação subjacente. Em relação a esse aspecto, Hoffmann (1991) destaca que as finalidades das práticas avaliativas estão profundamente interligadas ao conceito que o docente tem de avaliação e à pratica que utiliza no cotidiano escolar, bem como aos fins do processo de ensino e aprendizagem.

A autora aponta ainda que uma das principais finalidades do ato de avaliar é que ele contribua para a melhoria não só do produto final, mas do processo de ensino e aprendizagem. 
Salientamos que os objetivos da avaliação precisam estar claros não somente para os professores, mas também para os alunos. Segundo Luckesi (2002), o valor da avaliação encontra-se no fato de o aluno poder tomar conhecimento do porquê está sendo avaliado e assim verificar seus avanços e dificuldades. Por isso, cabe ao professor saber primeiro quais são as finalidades de suas práticas avaliativas para que, posteriormente, o aluno também possa se apropriar de tais informações.

De acordo com o autor, a avaliação no seio da atividade de aprendizagem é uma necessidade, tanto para o professor como para o aluno. A avaliação permite ao professor adquirir os conhecimentos que o tornem capaz de situar, do modo mais correto e eficaz possível, a ação de estímulo, de guia ao aluno. É papel do professor desafiá-lo a superar as dificuldades e fazer que ele continue progredindo na construção dos conhecimentos. Ao aluno, permite verificar em que aspectos ele deve melhorar durante seu processo de aprendizagem.

Em nossa análise das respostas dos alunos referentes à avaliação da aprendizagem, percebemos que muitos consideram o termo avaliação sinônimo de prova, e atribuem prioritariamente ao professor a tarefa de analisar e utilizar os resultados obtidos no processo avaliativo.

As respostas dos doze alunos foram semelhantes quanto ao conceito de avaliação da aprendizagem escolar. Esta homogeneidade permitiu agrupar sob uma única categoria:

Verificar o aprendizado/desempenho do aluno, isto é, permite saber o conhecimento assimilado ou adquirido pelo aluno: $91,6 \%$

Algumas respostas ilustram esta categoria:

A1: São provas que os professores fazem para saber como está o rendimento de seus alunos. São avaliações com o conteúdo que foi explicado pelo professor em sala de aula.

A2: São as avaliações feitas com o aluno para avaliar o que ele aprendeu com o professor.

A4: É uma maneira de ver se os alunos estão aprendendo o que o professor lhes passa.

Somente um dos alunos entrevistados colocou a avaliação sob a perspectiva do aluno:

A8: [...] é nós mesmos sabermos se compreendemos o que nos foi passado. 
Como podemos observar, as expressões "verificar" e "saber" o que o aluno aprendeu apareceram em praticamente todas as definições dos alunos e dos professores, revelando profunda semelhança na categorização das respostas.

$\mathrm{Na}$ questão referente às finalidades da avaliação, os alunos em sua unanimidade (100\%) foram enfáticos no aspecto verificação da aprendizagem.

A2: Serve para mostrar se houve um aprendizado do aluno sobre determinado conteúdo.

A3: Para o professor ver como está a aprendizagem do aluno.

A12: Para ver o desempenho individual de cada aluno sem livros, cadernos para ajudar.

A10: Para avaliar o aluno em determinada disciplina e para ver realmente se o aluno aprendeu ou não.

De acordo com nossas leituras, a utilidade da avaliação é fornecer subsídios mediatos para a correção do processo em direção ao objetivo; neste sentido, a avaliação educativa deve significar precisamente o cuidado com a qualidade do ensino. E isto não deve ser somente responsabilidade do professor, mas também do aluno, como afirma Luckesi (2002, p. 83):

A avaliação realizada com os alunos possibilita ao sistema de ensino verificar como está atingindo os seus objetivos, portanto, nesta avaliação ele tem uma possibilidade de autocompreensão. O professor, na medida em que está atento ao andamento dos seus alunos, poderá, através da avaliação da aprendizagem, verificar o quanto o seu trabalho está sendo eficiente e que desvios está tendo. O aluno, por sua vez, poderá estar permanentemente descobrindo em que nível de aprendizagem se encontra, dentro de sua atividade escolar, adquirindo consciência do seu limite e das necessidades de avanço. Além disso, os resultados manifestados por meio dos instrumentos de avaliação poderão auxiliar o aluno num processo de automotivação, na medida em que lhes fornece consciência dos níveis obtidos de aprendizagem.

No item três do questionário dos alunos, a pergunta destinava-se a verificar se eles acreditavam que a escola existiria sem avaliação. A maioria (75\%) respondeu que não, pois consideram o ato de avaliar essencial ao professor e à escola para saber como está o rendimento e a aprendizagem dos alunos. Algumas respostas selecionadas demonstram claramente isso:

A7: Não, porque sem a avaliação não teria meio de saber se o aluno aprendeu ou não. 
A12: Não, porque se não tivesse avaliação quase ninguém se interessaria com as matérias da aula.

A2: Não, porque muitos alunos não estudam mesmo tendo provas, imagine se não tivesse. A avaliação faz todos ter que revisar a matéria e estudar.

A4: Não, porque não teria como saber se o aluno aprendeu. E o aluno também não ia estudar, e se não estudasse não ia aprender. Então, não teria para que existir escola, porque a gente vai pra escola pra aprender, e a avaliação mostra se a gente aprendeu ou não.

Esta questão foi inspirada no texto de Maria Tereza Esteban (2002, p. 9), em que indaga: “[..] a escola poderia existir sem avaliação?"

Para estes alunos entrevistados, observamos que definitivamente não!

As respostas dos alunos a esta questão revelam que,

[...] sem a prova, o que obrigaria os alunos e alunas a estudar? Sem os prêmios e castigos, com seus mil apelidos e disfarces, como garantir a disciplina? Sem instrumentos de avaliação, como garantir que os conteúdos mínimos estão sendo aprendidos, como identificar quem sabe e quem não sabe, atendendo à função de credenciamento assumida pela escola? (Esteban, 2002, p. 10)

Como sinaliza a autora, talvez a avaliação seja um "mal necessário". Conclusão com que também concordariam muitos(as) pais e mães (ou responsáveis), seja por um argumento ou por outro.

Os demais alunos (25\%), mesmo respondendo que a escola existiria sem avaliação, mostraram preocupação com a aprendizagem, o que pode ser observado a seguir:

A1: Acho que poderia existir, mas o aluno não iria prestar atenção e aprender, porque não iria fazer prova sobre $\mathrm{o}$ assunto.

A2: Sim, mas os professores não iriam saber como anda o rendimento do aluno na escola, se ele entendeu ou não o conteúdo.

As respostas destes alunos evidenciam que a aprendizagem está de certa forma condicionada ao aspecto avaliativo, ou seja, eles estudam para fazer provas, para obter boas notas; enfim, para obter êxito nos estudos e passar de série. Elas destacam o papel da avaliação enquanto reguladora do processo de ensino e aprendizagem, uma vez que o professor só tem a garantia que o aluno vai realmente estudar e aprender se estiver condicionado ao aspecto avaliativo. E se não tivessem provas? Para que os alunos iriam 
estudar? Como prender a atenção da turma? Como fazer com que os alunos prestem atenção, realizem as atividades, se não serão avaliados?

Neste olhar, a avaliação torna-se uma faca de dois gumes: é essencial para mostrar ao professor e ao aluno se os objetivos de ensino e de aprendizagem estão sendo alcançados, apontando possíveis tomadas de decisão a respeito dos resultados obtidos, como também acaba, de certa maneira, fazendo com que os alunos tenham o foco dos seus estudos e da sua aprendizagem condicionados à avaliação.

Acreditamos ser este o grande desafio da escola hoje: promover uma prática pedagógica que leve os alunos a realmente aprenderem para a vida e não somente para as provas e trabalhos escolares.

A música de Gabriel, O Pensador, Estudo Errado, lançada em 1995, reafirma esse nosso desafio.

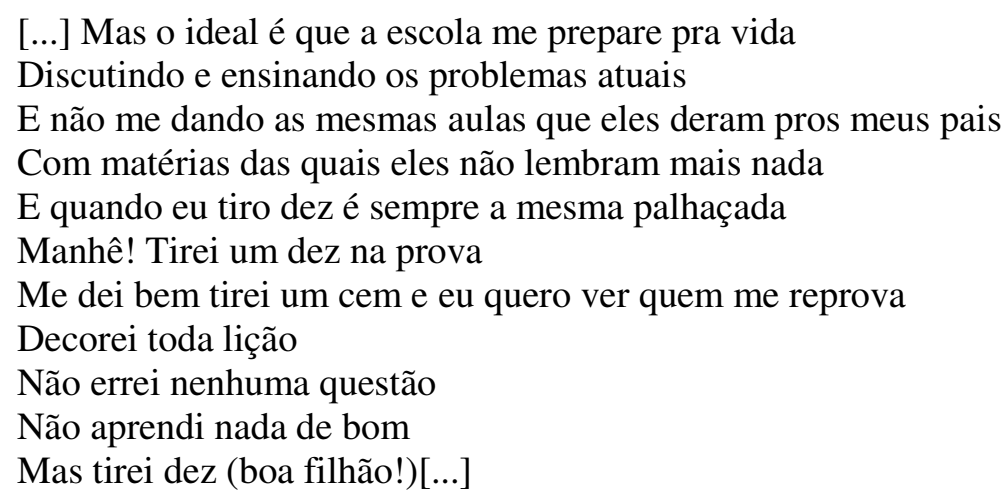

Segundo Perrenoud (1999), a função nuclear da avaliação é ajudar o aluno a aprender e ao professor ensinar, determinando também quanto e em que nível os objetivos estão sendo atingidos. Para isso, de acordo com Libâneo (1999) é necessário o uso de instrumentos e procedimentos de avaliação adequados. Sob essa perspectiva, nos interessou investigar também os instrumentos mais utilizados pelos professores em suas práticas avaliativas.

Pela análise das respostas, foi possível perceber a presença dos seguintes instrumentos: provas (orais, escritas, individuais, em duplas): 100\%; trabalhos (individuais, em duplas): $100 \%$. Estes dois instrumentos apareceram em todas as respostas dos professores pesquisados. Algumas evidenciam isso:

P2: Avalio através de provas orais, provas individuais ou em duplas. Como também através de trabalhos individuais ou em dupla.

P3: Trabalhos em duplas, provas individuais ou em duplas. 
P7: Trabalhos em duplas ou individuais com a ajuda do professor, provas individuais.

Os outros instrumentos citados foram: atividades em sala de aula (42\%); tarefas e caderno (16\%), mas sempre associados a outros: provas e trabalhos, os quais são comumente utilizados:

P4: Atividades em sala de aula e para casa, trabalhos e atividades em duplas, provas escritas e orais e organização das atividades no caderno.

P1: Através de provas individuais, em duplas, trabalhos com a intervenção do professor, tarefas de casa, atividades desenvolvidas em sala de aula, organização do caderno.

Tais instrumentos (atividades em sala, tarefas e caderno) apareceram em pouquíssimas respostas, revelando que os professores ainda mantêm a tradicional forma de avaliar por meio de provas e trabalhos. Entretanto, é possível observar alguns singelos vestígios de mudanças, como provas orais, trabalhos e provas em duplas.

Em relação aos instrumentos de avaliação, os alunos também foram questionados e confirmaram o que os professores responderam, sendo possível agrupá-los em quatro categorias: provas (avaliação: termo usado por alguns alunos como sinônimo de prova): 100\%; trabalhos: 100\%; atividades extras e domiciliares: $100 \%$ e organização do caderno: $33 \%$.

As respostas a seguir ilustram que os alunos pesquisados reconhecem os instrumentos de avaliação utilizados pelos professores de Matemática:

A2: Na disciplina de Matemática, somos avaliados através de provas, trabalhos, organização do caderno, atividades de sala de aula, tarefas domiciliares sobre os conteúdos que estão sendo trabalhados.

A7: Sou avaliado por provas, participação nas atividades de sala e trabalhos com base nos conteúdos aplicados.

A8: Provas, trabalho individual, trabalho em grupo, atividades.

A12: Através de provas, tarefas extras e trabalhos.

Consideramos, de certa forma, um pequeno avanço esta variedade de ferramentas de avaliação utilizadas pelos professores de Matemática, pois acreditamos que o docente que faz uso de instrumentos de avaliação diversos para, ao longo de um período, acompanhar o 
processo de ensino e aprendizagem, é diferente daquele que se restringe a dar uma prova ao final do período.

Salientamos, entretanto, que esta diversidade de instrumentos de avaliação se deve também à exigência da LDB no 9394/96, no artigo 24, capítulo V, bem como do Processo $n^{\circ}$ 091/99, deliberação no 007/99 do Estado do Paraná, que obriga legalmente os professores a utilizarem mais de um meio de aferição com seus alunos.

Luckesi (2002) enfatiza a importância dos instrumentos e critérios, pois a avaliação não poderá ser praticada sobre dados inventados pelo professor; este por sua vez deverá ter clareza dos objetivos de sua prática avaliativa, dos instrumentos que irá utilizar e dos critérios que serão analisados para cada instrumento.

Luckesi (1984) salienta que o critério deve ser utilizado como exigência de qualidade e não como forma de autoritarismo do professor para com o aluno. Outro perigo é de os critérios não serem formulados previamente e sim no decorrer da própria avaliação.

Neste contexto, a decisão do nível de aprendizagem a ser obtido pelo aluno dependerá muito da subjetividade do professor no momento em que exercita seu julgamento, pois o "humor" da personalidade varia não só conforme os padrões introjetados, mas também conforme os fatores circunstanciais momentâneos.

A tarefa de analisar resultados implica, num primeiro momento, a organização de todo o material; sua divisão em partes, que devem ser inter-relacionadas; a identificação de tendências e padrões relevantes. Na avaliação da aprendizagem, a análise mais formalizada de resultados acompanha a aplicação de um instrumento e dá sequência a replanejamentos e orientações para os alunos.

Desse modo, o educador de hoje precisa repensar os seus critérios de avaliação acerca da necessidade de construir políticas e práticas que considerem a diversidade e que estejam comprometidas com o sucesso e não com o fracasso escolar.

Nesse sentido, outra questão que merece ser analisada neste artigo é a que se refere à recuperação. A questão foi a seguinte: $O$ que é feito quando a maioria da turma tem um desempenho ruim em determinado assunto ou conteúdo que foi avaliado?

Os professores em sua unanimidade (100\%) responderam que retomam o conteúdo; poucos, todavia, se referiram às estratégias de ensino, enfatizaram apenas que realizam mais exercícios e atividades sobre o conteúdo que ficou falho.

P10: Explico novamente e procuro exercícios diferenciados para aplicar em sala. 
P5: Após a correção da provas ou trabalhos com os alunos, o conteúdo é explicado novamente, fazendo uma revisão do conteúdo dado. É dado exercícios para que o aluno possa praticar o que foi explicado, esses exercícios são corrigidos e posteriormente é realizada a recuperação paralela para que os alunos demonstrem seus avanços.

P7: Retomo desde as explicações, revejo as estratégias que utilizei e também como foram organizados os instrumentos de avaliação.

P3: Reforçando o conteúdo visto, trabalhando com novos métodos explicativos.

Percebemos que a maioria dos professores, por mais que estejam começando a delinear possíveis mudanças, ainda estão muito arraigados ao sistema de ensino platônico da Matemática conforme aponta Machado (1987), o qual se baseia em exercícios e atividades mecânicas, sem preocupar-se com o aspecto de apreensão de conceitos propriamente ditos, os quais na realidade são a base de qualquer aprendizagem matemática.

Mello (2000, p. 98) destaca que geralmente os professores acabam ensinando da forma como aprenderam, porque

[...] ninguém facilita o desenvolvimento daquilo que não teve oportunidade de aprimorar em si mesmo. Ninguém promove a aprendizagem daquilo que não domina, é preciso que o professor experimente, enquanto aluno aquilo que ele deverá ensinar a seus próprios alunos [...].

Na mesma perspectiva, D’Ambrósio (1993, p. 38) salienta que: “[...] dificilmente um professor de Matemática formado em um programa tradicional está preparado para enfrentar os desafios das modernas propostas curriculares". Concordamos com a autora e destacamos uma indagação: Como confiar que a Matemática possa ser aprendida de forma diferente, se os professores nunca tiveram semelhante experiência em sala de aula enquanto alunos?

Sendo assim, procuramos verificar a formação inicial que nossos professores pesquisados tiveram: todos possuem habilitação em Matemática e fazem cursos de formação continuada. Entretanto, conforme salienta Ponte (2002, p. 69):

[...] se a competência dos professores fosse medida pelo número de cursos frequentados, a qualificação dos professores seria extraordinária. Se a qualidade das escolas pudesse ser medida pelo peso de diplomas e certificados, já teria acontecido uma revolução em cada escola. Os professores acumulam "capacitações", sem que isso corresponda a mudança, ou responda aos desafios que encaram na sala de aula. 
D’Ambrósio (1993) sinaliza que é muito importante a formação teórica dos professores de Matemática, para que saibam lidar com as novas tendências educacionais e, dessa maneira, poder influenciar e contribuir para a transformação da prática avaliativa atual. Dada a formação do professor de Matemática apresentar falta de subsídios teóricos e metodológicos, sente dificuldade em alterar a prática avaliativa, pois sabemos que é difícil modificar o que foi instituído secularmente.

Os alunos também responderam à seguinte questão: $\mathrm{O}$ que é feito quando a maioria da turma tem um desempenho ruim em determinado assunto ou conteúdo que foi avaliado? Igualmente aos professores, os alunos foram unânimes ao responderem que o conteúdo é retomado. Algumas respostas ilustram esta única categoria:

A3: Ela volta a matéria e faz a revisão do conteúdo e depois aplica a prova de recuperação para os alunos que foram mal.

A6: Explica tudo novamente até que todos entendam.

A5: A professora faz revisão sobre o conteúdo antes das provas e se o aluno vai mal a professora retoma o conteúdo de novo e faz a recuperação.

A4: Ela se empenha para explicar melhor, pede para todos os alunos participarem da aula, faz mais atividades sobre o assunto.

A9: Ela revê o conteúdo, faz mais atividades explicando novamente.

As respostas dos alunos evidenciam mais ainda um ensino de Matemática sustentado pela repetição e memorização. Percebe-se o esforço do professor para que todos entendam o conteúdo; no entanto, o faz sempre do mesmo jeito: repetindo, explicando novamente, reafirmando sua postura platônica de ensinar Matemática. Esta constatação, por meio das respostas que obtivemos, é extremamente preocupante, pois nos dias atuais a atitude do professor explicar, explicar, repetir, repetir, e de os alunos fazerem e refazerem exercícios não é suficiente para garantir a aprendizagem, porque, para "bem enfrentar" o Terceiro Milênio, o século XXI, os estudantes necessitam, conforme aponta Pais (2002), de métodos de ensino adequados para a crescente ênfase em resolução de problemas, em aplicações e em desenvolver o raciocínio mais profundo, o qual não se faz somente pela repetição e memorização.

Na penúltima pergunta do conteúdo investigado em nosso instrumento de pesquisa, buscamos descobrir se há ou não um tratamento do erro cometido pelo aluno nas tarefas 
avaliativas e, desse modo, verificar como o professor atua diante do acontecimento das falhas e dos obstáculos cognitivos geradores dos erros conceituais ou sistemáticos de seus alunos.

As respostas, tanto dos professores quanto dos alunos, apontam que este não é trabalhado em sala de aula e quando o faz geralmente é de maneira ineficiente.

As respostas foram agrupadas em apenas uma categoria, pois evidenciam que os professores pesquisados (100\%) trabalham com o erro sob a mesma perspectiva: a deficiência cognitiva do aluno.

As respostas analisadas anteriormente nos levam a inferir que o sistema avaliativo do qual os professores pesquisados fazem parte, seus métodos, seus instrumentos, suas formas de recuperação de conteúdos, ignoram ou dão pouca atenção às tentativas que não resultaram em acerto imediato do aluno. Algumas respostas salientam isto:

P10: O erro é apontado e o aluno tem a oportunidade de verificar o que errou, ter novas explicações e acertar.

P9: Sim, trabalho. Quando observo o desempenho deles nas atividades já vou retomando e fazendo eles perceber os erros e rever.

P12: Os erros são corrigidos no quadro e é dado mais exercícios de fixação sobre os assuntos que mais erraram.

Torna-se evidente, pelas respostas obtidas, que os professores atribuem a causa dos erros cometidos pelos alunos à falta de conhecimento, para a qual preconizam a terapia clássica da repetição, da explicação e dos exercícios. O resultado, geralmente, é ineficaz.

As respostas dos alunos elucidam o que observamos nos depoimentos dos professores:

A5: Ele corrige no quadro, pergunta se todo mundo entendeu e depois passa de carteira em carteira vendo se todos compreenderam o erro cometido.

A3: Quando a gente erra, a professora revisa a matéria novamente de um jeito mais fácil e para que todos entendam.

A4: Durante as aulas, quando a matéria está sendo explicada, ela tira dúvidas, ajuda a enxergar onde erramos; já na prova só ganhamos nota no exercício que acertamos.

A importância de se conhecer o erro do aluno e em que pontos ele não consegue superar determinada dificuldade reside no fato de que ao lidar com os erros, o professor tem à sua disposição dados precisos para intervenções mais individualizadas, além de reconhecer as diferenças e dificuldades de seus alunos. Para Bertoni (2000, p. 45), “[...] o mais importante é 
o professor adotar uma atitude reflexiva diante do erro do aluno, procurando não apenas compreender o erro no interior de um contexto, mas também compreender o sujeito que erra".

De acordo com Esteban (2002, p. 21):

O erro oferece novas informações e formula novas perguntas sobre a dinâmica aprendizagem/desenvolvimento, individual e coletiva. O erro, muitas vezes, mais do que o acerto, revela o que a criança "sabe", colocando este saber numa perspectiva processual, indicando também aquilo que ela "ainda não sabe", portanto o que pode "vir a saber". Neste sentido, passa a ser um estímulo (ou um desafio) ao processo ensino/aprendizagem - estímulo para quem aprende e estímulo para quem ensina. $\mathrm{O}$ erro desvela a complexidade do processo de conhecimento, tecido simultaneamente pelo passado, pelo presente e pelo devir.

Em relação ao trabalho realizado com o erro do aluno, destacamos ser de fundamental importância que os professores revejam o tratamento que é dado durante o processo de ensino e aprendizagem, principalmente no que se refere às práticas avaliativas, procurando descobrir o porquê de o aluno errar, as particularidades dos obstáculos cognitivos e a qualidade das falhas cometidas. Dessa maneira, o professor poderá intervir, oferecendo a explicação ou o conhecimento que falta ao aluno para que dê o passo na direção da aprendizagem adequada. Essa mediação incide no que Vygostky (1994) nomeou de zona de desenvolvimento proximal, ou seja, trabalhando com o erro do aluno segundo, Esteban (2002), o professor poderá intervir onde o aluno ainda "não sabe" para que ele possa "vir a saber".

A última pergunta analisada, do questionário realizado com os professores, solicitava que apontassem as três maiores dificuldades com relação à avaliação da aprendizagem de seus alunos.

Foi possível agrupar as dificuldades apontadas em três categorias:

- Trabalhar com o erro do aluno e devolutiva das provas e trabalhos (28\%).

P5: Trabalhar com o erro dos alunos, pois existem situações em que o aluno sabe resolver determinado exercício, porém por distração erra. Como avaliar neste caso? Outro problema é o trabalho com as crianças que possuem dificuldades comprovadas. Até que ponto devo olhar diferente para não excluir, e como auxiliar este aluno, como dar as provas e trabalhos para elas?

P10: A maior dificuldade é trabalhar com a devolutiva das provas e dos trabalhos, pois há pouco tempo para se fazer um trabalho realmente bom, logo depois de constatadas falhas na aprendizagem. 
- Grande número de alunos por sala e aspectos referentes ao desinteresse demonstrado pelos alunos: $(56 \%)$.

P7: Número de alunos por sala, os níveis muito heterogêneos de aprendizagem e interesse dos alunos em aprender.

P8: É muito complicado avaliar o aluno pelo seu desempenho em sala, pois o descaso deles é muito grande, aí fica difícil saber se aprendeu ou não.

- Elaboração justa e correta das provas e avaliar corretamente - instrumentos de avaliação (16\%).

P2: Qual o nível de prova aplicar, quantas provas e quantos trabalhos e a forma mais correta de saber se o aluno aprendeu.

P3: Estabelecimento de critérios para a elaboração e correção das provas e dos trabalhos, como também de que forma elaborar corretamente os instrumentos que usamos para avaliar.

Em relação às dificuldades apontadas pelos professores, estas indicam o quanto é complexo o ato de avaliar e quão múltiplas facetas ele apresenta.

De acordo com a nossa análise, ainda não foi notada uma busca reflexiva sobre a prática pedagógica destes professores. Por isso, enfatizamos a necessidade urgente dos professores refletirem sobre sua prática pedagógica. De acordo com Hoffmann (1991), a prática reflexiva supõe voltar-se "para dentro" de si mesmo. Implica saber que refletir para agir significa assumir, na prática, o raciocínio e o espírito do projeto; significa valorizar o planejamento de ação e utilizar a avaliação como forma de regulação e observação do que ainda não aconteceu, mas sobre o que já definimos um valor e um modo de intervenção.

A última pergunta feita aos alunos, que mereceu nossa análise foi: A forma de avaliação que seu professor de Matemática utiliza favorece a sua aprendizagem? Nas respostas, os alunos foram unânimes dizendo que sim, apontando o fato de o professor "explicar bem a matéria" e "usar várias formas de avaliar".

As respostas abaixo ilustram as nossas observações a esse respeito:

A4: Sim, porque ela só avalia quando ela procura explicar até que todos entendam.

A8: Acho que sim, porque a explicação, os exercícios feitos na sala esclarecem a maior parte das dúvidas dos alunos. E quando vamos às provas fica mais fácil. 
A9: Sim, porque ela nos avalia de muitas maneiras que faz com que nossa aprendizagem seja cobrada.

A3: Sim, porque ela não dá só provas, mas também trabalhos, exercícios diferentes que fazem a gente quebrar a cabeça e aprender de verdade e não só decorar.

Evidencia-se, por meio das respostas dos alunos pesquisados, que a forma de avaliação utilizada pelos professores é bem aceita pelos alunos, pois estes já estão, de certa maneira, acostumados com esta cultura escolar de avaliação.

A chamada "cultura da avaliação", atualmente tão presente nos processos educacionais e que, muitas vezes, tem condicionado as práticas curriculares, a organização do trabalho pedagógico escolar e as próprias práticas avaliativas na tentativa de adequá-las às exigências de tal "cultura", têm contribuído para a manutenção de uma avaliação escolar "certificativa", perdendo cada vez mais seu sentido pedagógico. Por outro lado, essa nossa preocupação caminha no sentido de reafirmar a importância que a avaliação tem como prática central no trabalho pedagógico, mas não por ser mais valiosa que as próprias finalidades desse trabalho, ou por essas finalidades se justificarem apenas pela iminência de serem avaliadas. A importância central da avaliação está em (dever) ser capaz de mediar a prática educativa, contribuindo significativamente para que as suas finalidades sejam alcançadas e, inclusive, possam até ser (re)significadas.

\section{CONSIDERAÇÕES FINAIS}

O discurso dos professores e alunos nos revela o quão complexa e desafiante é a tarefa da avaliação da aprendizagem no cotidiano escolar. Na tecitura desse discurso, podemos desvelar o lugar que ela ocupa no processo de ensino e aprendizagem e a importância que desempenha nesse mesmo processo.

Conscientes de que não existem respostas prontas e acabadas, procuramos respeitar e analisar cuidadosamente as respostas obtidas. Não pretendendo esgotar os estudos sobre avaliação, procuramos, na medida do possível, fazer uma análise cautelosa apoiada na literatura citada, sem a pretensão de apontar soluções para a prática da avaliação. Acreditamos que seria, no mínimo, incoerente listar uma série de aspectos negativos que se constituem em implicações no processo avaliativo. Todavia não foi esse nosso intuito.

O confronto das respostas obtidas, dos professores e alunos pesquisados, com a literatura especializada à qual tivemos acesso, apontou a necessidade de se discutir a 
avaliação, principalmente em relação à Matemática, pois verificamos que a forma de avaliar da maioria dos professores, apesar de revelar algumas pequenas mudanças e a utilização de instrumentos diversos, ainda se apresenta sem a devida compreensão do significado do erro e da verdadeira concepção de recuperação. Cabe destacar que os resultados analisados mostram que muitas das situações que parecem estar mudando na realidade não estão, pois observamos que continuam a reproduzir concepções de ensino e aprendizagem ainda aquém do desejável para se constituir um ensino de Matemática realmente de qualidade.

De acordo com a literatura pesquisada, o processo de avaliação da aprendizagem inclui a obtenção contínua de dados quantitativos e qualitativos acerca da extensão e natureza da aprendizagem do aluno. Assim, todas as informações disponíveis sobre o desempenho acadêmico são úteis, tanto para professores quanto para alunos, porque subsidiarão o julgamento do valor dos resultados e a tomada de decisões relativas aos progressos e às dificuldades que podem ocorrer durante o processo de ensino e aprendizagem.

Este ajuizamento de valor dos resultados de aprendizagem depende do conceito que o professor tem do processo de avaliação, que por sua vez, determina o que e como ele avalia. Deste modo, as possibilidades de mudanças nas práticas de avaliação requerem a compreensão, pelo professor, de que os diversos modelos de ensino e aprendizagem implicam abordagens de avaliação diferenciadas.

Assim, rever a concepção de avaliação e os aspectos a ela subjacentes é rever certamente as concepções de ensino e aprendizagem, de educação e de escola, apoiadas em princípios e valores comprometidos com a instituição do aluno cidadão. Quando isso for colocado em prática, a avaliação será vista como função diagnóstica, dialógica e transformadora da realidade escolar.

Mudar, muitas vezes, é um processo penoso, já que procedimentos e atitudes avaliativas tradicionais e inadequadas para o tempo em que vivemos se encontram profundamente enraizados nos professores e alunos. No entanto, cabe aos professores acreditarem, apesar dos inúmeros obstáculos, que é possível realizar no cotidiano escolar uma avaliação da aprendizagem com ênfase na tomada de decisões para garantir o sucesso do aluno e consequentemente da prática pedagógica do professor, pois, segundo Esteban (2002), toda resposta ao processo de aprendizagem, seja certa ou errada, é um ponto de chegada, por mostrar os conhecimentos que já foram construídos e absorvidos, e um novo ponto de partida, para um recomeço, possibilitando novas tomadas de decisões. 
A realização deste trabalho representou uma tentativa de sistematizar um rico conjunto de dados disponíveis e de fornecer algumas interpretações possíveis relativas ao tema. Esperase, com a disseminação de seus resultados, ter contribuído para desestabilizar acepções cristalizadas, assim como para subsidiar discussões em torno da temática abordada, contribuindo de certa maneira para a melhoria da qualidade do ensino de Matemática das séries finais do ensino fundamental, no que se refere às práticas de avaliação da aprendizagem, porque acreditamos que o importante não é fazer como se cada um tivesse aprendido, mas permitir a cada um aprender.

\section{REFERÊNCIAS BIBLIOGRÁFICAS}

BARDIN, L. Análise de conteúdo. Lisboa: Edições 70, 1979.

BERTONI, N. O Erro como estratégia didática. Campinas: Papirus, 2000.

BRASIL. Lei $n .^{\circ}$ 9394. Lei de Diretrizes e Bases da Educação Nacional. Disponível em: <http://www.planalto.gov.br/CCIVIL_03/LEIS/L9394.htm>. Acesso em: 10 set. 2007.

D’AMBRÓSIO, B. S. Formação de professores de matemática para o século XXI: o grande desafio. Pró-Posições, v. 4, n. 1, 1993.

ESTEBAN, M. T. A Avaliação no cotidiano escolar. In: (Org.). Avaliação: uma prática em busca de novos sentidos. 4. ed. Rio de Janeiro: DP\&A, 2002. p. 7-28.

GABRIEL PENSADOR. Estudo errado. Disponível em:

<http://pt.wikipedia.org/wiki/Gabriel,_O_Pensador>. Acesso em: 15 abr. 2007.

HOFFMANN, J. Avaliação mito \& desafio, uma perspectiva construtivista.

Porto Alegre: Mediação, 1991.

LIBÂNEO, J. C. Didática. 15.ed. São Paulo: Cortez, 1999.

LUCKESI, C. C. Avaliação da aprendizagem escolar. 14. ed. São Paulo: Cortez, 2002. Cortez, 1998.

Avaliação da aprendizagem escolar: estudos e proposições. 8. ed. São Paulo:

Avaliação educacional escolar; para além do autoritarismo. Tecnologia

Educacional, v.13, p. 6-15, 1984.

MACHADO, N. J. Matemática e realidade: análise dos pressupostos filosóficos que fundamentam o ensino da matemática. São Paulo: Cortez, 1987.

MELLO, G. N. Formação inicial de professores para a educação básica: uma (re)visão radical. São Paulo em Perspectiva, v. 14, n. 1, p. 98-110, 2000. 
PAIS, L. C. Didática da matemática: uma análise da influência francesa. 2. ed. Belo Horizonte: Autêntica, 2002.

PERRENOUD, P. Avaliação: da excelência a regulação das aprendizagens. Porto Alegre: Artes Médicas Sul, 1999.

PONTE, J. P. Investigar a nossa própria prática. In: Reflectir e investigar sobre a prática profissional. Lisboa: APM, 2002. p. 5-28.

VYGOTSKY, L. S. A Formação social da mente. 2. ed. São Paulo: Martins Fontes, 1994.

Recebido em: fevereiro 2009

Aprovado para publicação em: setembro 2009 